\title{
Urgences
}

\section{Tempête d'amours dans un verre d'eau-de-vie}

\section{Gilbert Dupuis}

Numéro 4, 2e trimestre 1982

URI : https://id.erudit.org/iderudit/025065ar

DOI : https://doi.org/10.7202/025065ar

Aller au sommaire du numéro

Éditeur(s)

Urgences

ISSN

0226-9554 (imprimé)

1927-3924 (numérique)

Découvrir la revue

Citer ce document

Dupuis, G. (1982). Tempête d'amours dans un verre d'eau-de-vie. Urgences, (4), 81-86. https://doi.org/10.7202/025065ar

Ce document est protégé par la loi sur le droit d'auteur. L'utilisation des services d'Érudit (y compris la reproduction) est assujettie à sa politique d'utilisation que vous pouvez consulter en ligne.

https://apropos.erudit.org/fr/usagers/politique-dutilisation/
Cet article est diffusé et préservé par Érudit.

Érudit est un consortium interuniversitaire sans but lucratif composé de l'Université de Montréal, l'Université Laval et l'Université du Québec à Montréal. Il a pour mission la promotion et la valorisation de la recherche. https://www.erudit.org/fr/ 
GILBERT DUPUIS

\section{Tempête d'amours dans un verre d'eau-de-vie}


Et la porte que Prunelle referma derrière elle ne fit même pas de bruit. Seules quelques semelles assourdies par le tapis du corridor précipitèrent Raviluc dans un hiver intérieur.

L'homme reste d'abord de glace devant le panneau de contreplaqué qui lui sert de table de travail. Elle est partie j'entends sa mécanique vrombir. Le silence neige en abondance dans l'appartement; il boit toutes les trente secondes une pleine gorge de vin rouge, jusqu'à débordement aux commissures. Les yeux désormais plus verts.

Brusquement, I'homme projette à travers la pièce une coupe douloureusement vide. II se lève et marche jusqu'au tourne-disque. Vingt secondes et Jacques Brel mord dans une ode aux amoureux des aéroports. Ils seraient plus de deux mille mais ne feraient que deux. Raviluc maximise la poitrine de l'électrophone et fait péter la gueule de liège d'une autre bouteille de rouge ennobli jusqu'à douze pourcent. Et pour fêter ce titre, il offre son pied au téléviseur qui brise sa laisse électrique, tombe sur un cactus puis glisse aveugle l'écran contre le plancher. Elle est partie soulagée comme quand on change de chaîne après un mauvais show.

Raviluc prend une belle lampée de liquide rouge à même la bouteille tenue de sa main du coeur, il arrache de la main droite toutes les affiches des murs de son purgatoire: Les montres molles de Salvator Dali, Les Vacances, c'est Folio, Je vis en harmonie avec Environnement-Québec. Oui les quatre dessins de son fils aussi. Piétinées toutes les couleurs sous ses semelles lourdes, balayées toutes les fleurs du décor par le concierge des circonstances. Elle est partie le pied léger et le printemps propre. 
Gueule toujours Brel maudit Jack-in-the-box de l'âme, elle est partie cueillir le blé dans l'été de campagnes étrangères. Et Raviluc fume à briquet rouge dans son cube trop petit pour sa flamme. II ouvre avec violence la porte du frigidaire et casse la penture du haut et s'écrasent des oeufs blancs à la douzaine. Elle a craqué quand il commençait à naître...

Quand on a que l'amour. Chante barbu tardif génial et cancéreux, chante maudit artiste du verbe, chante la vie qui te quitte, chante masochiste millionnaire pour les écorchés, chante Breldu-Christ inavoué dans tes accordéons musette, tonne dans mes haut-parleurs que je roule mieux mes airs de sauvage. La chaleur sous ce chandail de laine trop petit mon dieu cette sueur de tonneau vide. Encore une autre gorgée pour tasser dans sa poitrine cette âcreté de la solitude sous tant de watts blancs dans les yeux. Mourir cela n'est rien, mourir la belle affaire. Elle est meurtrie c'est sûr dans ses ailleurs.

Raviluc, la bonbonne de larmes toujours à bout de bras, frappe dans la bibliothèque sortie du grand livre des soeurs du Saint-Rosaire. II cogne jusqu'à ce que le meuble vomisse à ses pieds tout Boris Vian, tout Jacques Prévert et beaucoup d'Alfred Jarry. II se perd dans la galaxie Gutenberg et file comète étouffante loin de ces livres inutiles pour l'heure. Je te donnerai des perles de pluie venues d'un pays où il ne pleut pas. Chante satané belge crotté par 6000 concerts, crève dans mes oreilles profanes, laisse-moi dans mes mots toi aussi. Prunelle les plus belles fesses blanches de la messe, Prunelle pur satin sous mes doigts $d^{\prime}$ inutile artisan du progrès technique, Prunelle mon coeur de braise héréditaire dans ta carapace de bouleau gelé, Prunelle partie faire l'ordinaire des amitiés diluantes, Prunelle mon âme de marmelade dans les mouillures rares des aubes dominicales, Prunelle ma noblesse du cul délivré de la banale comptabilité des faits et gestes, Prunelle ma femme de chair et du sublime entre mes draps à fleurs séchées du sperme mal convaincu entre tes lèvres, $\delta$ Prunelle ma fulgurance lumineuse traversant en musique sacrée ma cervelle athée de l'amour. 
Mais chante encore dieu barbu des derniers jours pour tous les attendris d'Orly et de Mont-Joli. Et vlan dans le miroir la bouteille vide de raisin liquéfié. Le ciel en zigzag répète en partie le clown caché sous le velours cordé et la laine de Hong Kong, le ciel se brise en pointes pour faire mal à Raviluc rouge jusqu'au nez et grave jusqu'au muscle entre ses cuisses. Prunelle mon ange de soie déchirée remet le vin et la cigarette à la mode du petit condamné, du petit porteur de sa douleur entre ses côtes maigres et ridicules sur les plages. Prunelle quelques milliards de molécules harmonieusement réparties au soleil par quelqu'énergie soufflante et sachant le nom des fleurs, Prunelle jadis gaspilleuse de ta saumure sur ma langue équivoque, paternelle et ravie. Mais elle est disparue dans l'oxygène lointain pour sa survie je me doute.

Chante donc Jacques Brel avant que de partir aussi, pousse ta gorge malade dans les profondeurs du chagrin universel, ne me quitte pas mon père acteur du vibrateur grandeur nature dans le béton de la Manicouagan d'ici. Dix-huit mois, trente ans mon père sur ce barrage entre toi et moi. Toute cette eau-de-vie désendiguée. Je sais p'pa que tu t'en fous de l'émotion de ma queue dans son humidité initiatique, tu as ta bedaine de houblon, ta jambe de métal et ta couette peroxydée à vivre, je te sens t'en foutre quand ses yeux de renard straight me trouent le plexus au-dessus de l'autel de clap-board et du goupillon de graphite, mes béquilles. Mon père mal aimant mal aimé dans les brumes fatales du silence couvé trop longtemps. Moi Raviluc des colonies gaspésiennes arrivé d'où je parle par l'urgence de sortir du rang St-François et par l'ouie renfoncée d'une marraine officieuse dans les mitraillettes à pédales de la General Electric, je te chante Prunelle sans accordéon derrière mes attachements d'instinct et mes élans d'amérique les yeux rougis vers ton respir magique et ta musique essentielle, je me reconnais du milieu de ma vie esclave de tes silhouettes aériennes et de tes hanches jadis hospitalières. Je titube que je vous aime du passé de la solitude et de l'inconnu, je le sens les jours mêmes que je marche bien droit devant. Tu es si frileuse pour mon avenir prenant frimas de toutes parts. 
Chante mon fou de l'accordéon et de la musique en bouche et du désespoir si bien garroché qu'il déleste, tourne ma galette de plastique si bien sillonnée de râlements poétiques oui mon bras lecteur et ma tête stéréophonique prenez et mangez ceci est mon sang, chante je t'aime, toujours les mêmes égratignures au visage affamé de caresses, toujours ces blessures au téléjournal à force de faire la bombe à neutrons, toujours ces nouvelles qui nous rasent à la mousse d'urée formaldéhide pour nous isoler toujours davantage... Chante pourquoi pas la complainte usée de mon grand-père trente ans derrière, mon aïeul défricheur et tuberculeux au bord de son cercueil sous mes yeux éblouis par les costumes noirs et le noyer verni. C'était au mois d'octobre à StJoseph d'Alma, malgré qu'ma vie est sobre ell' doit se finir là, qu'il chantait, le chapeau plein d'huile à gosser des écorces de peuplier en forme de croix du dernier recours. Davantage de soleil sur l'aluminium de la cuisine d'été que dans tous les voyages et les chansons racontés avant sa sortie côté pissenlits. Elle est partielle j'en suis sûr dans sa liberté chancelante.

Mais moi Raviluc des appartements ravagés par la tornade Prunelle, je souffre d'un manque de miel au côté gauche, mon âme de jello je dis tremble dans ma poitrine inhabitable et mal consolée par des choeurs et orchestres lâchés en circuit fermé. Ah! cette porte close sans décibel de rage dans l'air! Je les espère encore ses branches givrées courber s'émouvoir quand mes caresses perdront le nord dans son cercle polaire. Me reviennent ces photos couleurs sur papier glacé, trois fois coulé au bromure $\mathrm{d}^{\prime}$ argent ton profil pourtant soleil surpris à deux mètres d'un bar laitier couru par des citadins déshydratés solitaires tireurs de langue aux nuages aussi, mais où es-tu ma pourvoyeuse de voies lactées?

Raviluc va coller son front au bois gris de la porte morte depuis deux heures. II n'a plus que son amère salive pour élixir d'esquive. Mon dieu sa bouche si douce à boire aux temps des soifs communicantes. Chante chante mon ami avec tout le pathos de ta voix musette, chante encore avant que la nuit ne tombe sur les avions monoplaces au-dessus de Tahiti, chante les toutes nos ronnes de lait caillé. Enchante-moi Prunelle dans 
tes allures de courtisane rose, module les désarrois de l'amoureux flou aux banalités javellisantes des jours et des jours à gogo, oublie nos têtes de boucane nerveuse et chante avec moi les coeurs de jello mal pris dans la minute sereine du bonheur fugace et de la paix papillotante.

Tout ça n'est qu'une tempête dans un verre d'eau, qu'une tempête d'amours dans un verre d'eau-de-vie... Que la crasse dans l'oeil d'une oiselle de Pluton vue de la lune. Voilà le résidu du vide dans mes yeux cilleurs entre deux déglutitions du sablier.

Il me reste qu'ils chantent tous les Brel à l'eau de source, qu'ils intègrent bien la folie tous les enfants du temps trouble, il nous reste nos cris à tue-tête, nos jouets à tue-monde aussi, il nous reste toute la sève de l'arbre généalogique de I'humanité et tout le sucre de sa propre tête à répandre car quand on a tout perdu ou tout à perdre je dis comme ça qu'il nous reste encore soi à gagner... 